\title{
Commentary \\ Familial breast cancer and the hCHK2 1100delC mutation: assessing cancer risk
}

Jenny Varley ${ }^{1}$ and Daniel A Haber ${ }^{2}$

${ }^{1}$ CR-UK Department of Cancer Genetics, Paterson Institute for Cancer Research, Manchester, UK

${ }^{2}$ Massachusetts General Hospital Centre for Cancer Risk Analysis and Harvard Medical School, Charlestown, Massachusetts, USA

Corresponding author: Jenny Varley (e-mail: jvarley@picr.man.ac.uk)

Published: 20 February 2003

Breast Cancer Res 2003, 5:123-125 (DOI 10.1186/bcr582)

(C) 2003 BioMed Central Ltd (Print ISSN 1465-5411; Online ISSN 1465-542X)

\begin{abstract}
Germline mutations in the human checkpoint gene, $h C H K 2$, were first identified in 1999 in cases of Li-Fraumeni syndrome. Recent studies have demonstrated that the $h \mathrm{CHK} 21100 \mathrm{delC}$ mutation acts as a low-penetrance tumour suppressor gene in familial breast cancer not associated with mutations in $B R C A 1$ or BRCA2. The present article describes the published studies on $h C H K 21100$ delC and addresses some of the key questions raised.
\end{abstract}

Keywords: breast, familial, $h \mathrm{CHK} 2, \mathrm{Li}-$ Fraumeni, penetrance

\section{Introduction}

A remarkable, albeit unexplained, feature of genes implicated in familial breast cancer is their apparent function within a cellular pathway designed to monitor and repair damage to DNA. BRCA1 and BRCA2 are thought to be components of the cellular machinery involved in the repair of chromosomal breaks through homologous recombination. TP53, the quintessential tumour suppressor gene, regulates an essential checkpoint that is activated in response to DNA damage and mediates both cell cycle arrest and apoptosis. Whereas the breast cancer risk associated with mutations in BRCA1 or BRCA2 far exceeds the risk for other types of cancer (e.g. ovarian cancer and pancreatic cancer), germline mutations in TP53 confer a high degree of susceptibility to many types of cancer, including breast cancer, bone and soft-tissue sarcomas, brain and adrenocortical tumours - so-called Li-Fraumeni Syndrome (LFS).

Strict clinical definitions have been established for the classical form of LFS [1] and for a broader Li-Fraumeni-like syndrome [2]. Germline mutations in TP53 are present in around $80 \%$ of families with LFS and in $40 \%$ of those with Li-Fraumeni-like syndrome [3]. The genetic lesion in families lacking abnormalities in TP53 is unknown, but the mul- tiple cases of rare cancers arising at early ages makes it highly unlikely that these result from a chance aggregation.

Efforts at identifying subtle alterations in TP53 gene regulatory sequences have been unsuccessful, as has been the screening of many candidate tumour suppressor genes, including PTEN, p16, MDM2, bc/10, p63 and hChk1 (for a recent review, see [3]). A classic LFS family with wild-type TP53, however, was found to harbour a mutation in the cell cycle checkpoint kinase hCHK2, which segregated with cancer susceptibility and demonstrated somatic loss of heterozygosity [4,5]. The mutation 1100 delC results in a frameshift within the kinase catalytic domain, and encodes a nonfunctional protein [6].

\section{The hCHK2 1100delC mutation: a high- penetrance or low-penetrance predisposition gene?}

$h \mathrm{CHK} 2$ was initially identified as a potential tumour suppressor gene by virtue of its function within the DNA damage checkpoint in the yeast strain Schizosaccharomyces pombe. The yeast ortholog, Cds1, is activated by the ortholog of the ataxia-telangiectasia mutated (ATM) protein, Rad3, and in turn phosphorylates Cdc25, triggering a G2/M cell cycle arrest. In mammalian cells, however, 
the functional pathway appears more complex. hCHK2 is phosphorylated by ATM following DNA damage, but its phosphorylation targets include CDC25A, CDC25C, p53, and BRCA1 (for reviews, see $[7,8]$ ). hCHK2 therefore functions at a critical intersection of cellular pathways involved in the response to DNA damage.

The clinical spectrum of cancers associated with germline $h \mathrm{CHK} 2$ mutations may reflect their relative contribution toward the function of p53 and/or BRCA1. A small number of $h$ CHK2 mutations have now been identified in families with either LFS or Li-Fraumeni-like syndrome. These include the frameshift 1100delC [4,9] and the missense mutation R145W, which encodes a grossly unstable protein [5]. Another missense mutation, I157T, is of uncertain significance, since it exhibits defective in vitro phosphorylation of CDC25A and BRCA1 [10], yet it is present in $2-6 \%$ of the Finnish population where it appears to be associated with only a small, if any, increase in cancer risk.

While the $h C H K 2$ 1100delC mutation clearly encodes a nonfunctional protein, the tumour spectrum initially reported with this germline mutation ranges from classic LFS [4] to atypical Li-Fraumeni-like syndrome, with a predominance of early-onset breast cancer [9]. Most recently, population-based analyses have demonstrated that this specific mutation is present in approximately $1 \%$ of the population and that it confers a moderately increased risk for breast cancer [9].

An international consortium undertaking a genome-wide linkage analysis in breast cancer families lacking $B R C A 1 / B R C A 2$ mutations identified one large family in which a complex pattern of inheritance of cancer susceptibility pointed to the $h$ CHK2 gene on chromosome 22 . A number of individuals within this pedigree (but not all) who had breast and some other cancers were found to harbour the $1100 \mathrm{delC}$ mutation. The consortium went on to undertake a large-scale population study of control individuals $(n=1620)$, of individuals with breast cancer unselected for family history $(n=636)$, of cases from families with a family history but no $B R C A 1 / B R C A 2$ mutation $(n=1071)$ and of cases from BRCA1/BRCA2 families $(n=520)$. The $h C H K 21100$ delC mutation was present in $1.1 \%$ of the control group and in 1.4\% of breast cancer cases unselected for family history. In familial cases of breast cancer lacking a BRCA1/BRCA2 mutation, however, the frequency of the $h C H K 21100$ delC mutation was significantly elevated, at $5.1 \%(P=0.00000003)$. In families with the highest risk factors (identified by an increasing number of female breast cancer or a case of male breast cancer), the frequency was as high as 13.5\% [11]. The authors calculated the risk conferred by the $h \mathrm{CHK} 2$ 1100 delC variant as 1.7 in females and as 10.28 in males (under a simple model where $h C H K 2$ and other genes of female breast cancer and $9 \%$ of male breast cancer is attributable to the $h \mathrm{CHK} 21100 \mathrm{delC}$ variant. Finally, the observation that the prevalence of the $h$ CHK2 1100delC mutation was only $1 \%$ in familial cases known to carry mutations in BRCA1 led the authors to postulate that inactivation of these two genes may be functionally redundant, consistent with the known phosphorylation of BRCA1 by hCHK2 following DNA damage.

These observations were supported by a Finnish population-based study, which reported a population frequency of the $h C H K 21100$ delC mutation of $1.4 \%$, compared with a prevalence of $2.0 \%$ in sporadic breast cancer cases (odds ratio $=1.48, P=0.182$ ), and reported a frequency of $3.1 \%$ in one cohort of familial cases (odds ratio $=2.27, P=0.021)$ and of $5.5 \%$ in a second independent cohort of familial breast cancer (odds ratio $=4.2$, $P=0.0002)[12]$.

Taken together, these population-based studies indicate that $h C H K 21100$ delC is a relatively common mutation in the population, which functions as a low-penetrance susceptibility gene for breast cancer $[11,12]$.

\section{Unanswered questions}

These studies leave a number of unanswered questions. Does the $h$ CHK2 1100delC mutation confer an increased risk for different tumours in addition to breast cancer, and how can we reconcile its low-penetrant phenotype based on population studies with its initial discovery in the highly penetrant LFS?

One possible explanation is selection bias in the analysis of cancer pedigrees. As amply demonstrated for $B R C A 1 / B R C A 2$ mutations, the cancer risk derived from analyses of cancer kindreds is exaggerated by virtue of selection criteria aimed at collecting families in which most mutation carriers have developed breast cancer. A second explanation invokes the contribution of modifier genes, additional genetic variants in the population that may modulate the effect of $h \mathrm{CHK} 2$ mutations in different families. Whether one or both of these explanations contribute to the different phenotypes reported for the $h C H K 2$ $1100 \mathrm{del}$ C mutation, it remains possible that this mutation does confer an increased risk for tumours in addition to breast cancer, such as LFS-associated cancers that demonstrate somatic loss of heterozygosity. However, no statistically significant increase in risk for other tumours was noted in a population-based study [11].

Further definition of the cellular hCHK2 pathway (i.e. the relative physiological significance of its phosphorylation of p53 versus BRCA1) will also help clarify its place in the pantheon of tumour suppressor genes. What then should clinicians say to women with familial breast cancer who are found to harbour the hCHK2 1100delC mutation? 
Guidelines for genetic counselling in patients with lowpenetrant mutations are not well established, and in some ways may be akin to recommendations for women who are found to have precursor lesions following an abnormal mammogram and are at moderate risk for developing breast cancer. The optimal timing and frequency of screening mammography and the potential utility of antioestrogenic chemoprevention in carriers of the hCHK2 1100 delC mutation remain to be determined.

\section{Competing interests}

None declared.

\section{Referencess}

1. Li FP, Fraumeni JF, Mulvihill JJ, Blattner WA, Dreyfus MG, Tucker MA, Miller RW: A cancer family syndrome in twenty-four kindreds. Cancer Res 1988, 48:5358-5362.

2. Birch JM, Hartley AL, Tricker KJ, Prosser J, Condie A, Kelsey AM, Harris M, Morris Jones PH, Binchy A, Crowther D, Craft AW, Eden OB, Evans DGR, Thompson E, Mann JR, Martin J, Mitchell ELD, Santibanez-Koref MF: Prevalence and diversity of constitutional mutations in the p53 gene among 21 Li-Fraumeni families. Cancer Res 1994, 54:1298-1304.

3. Varley JM: Germline TP53 mutations and Li-Fraumeni Syndrome. Mut Res 2003, in press.

4. Bell DW, Varley JM, Szydlo TE, Kang DH, Wahrer DCR, Shannon $\mathrm{KE}$, Lubratovich M, Verselis SJ, Isselbacher KJ, Fraumeni JF, Birch JM, Li FP, Garber JE, Haber DA: Heterozygous germ line hCHK2 mutations in Li-Fraumeni Syndrome. Science 1999, 286:2528-2531.

5. Lee SB, Kim SH, Bell DW, Wahrer DCR, Schiripo TA, Jorczak MM, Sgroi D, Garber JE, Li FP, Nichols KE, Varley JM, Godwin AK, Shannon KE, Harlow E, Haber DA: Destabilization of CHK2 by a missense mutation associated with Li-Fraumeni Syndrome. Cancer Res 2001, 61:8062-8067.

6. Wu X, Webster SR, Chen J: Characterization of tumor-associated Chk2 mutations. J Biol Chem 2001, 276:2971-2974.

7. Rhind N, Russell P: Chk1 and Cds1: linchpins of the DNA damage and replication checkpoint pathways. J Cell Sci 2000, 113:3889-3896.

8. Zhou B-BS, Elledge SJ: The DNA damage response: putting checkpoints into perspective. Nature 2000, 408:433-439.

9. Vahteristo $\mathrm{P}$, Tamminen A, Karvinen $\mathrm{P}$, Eerola $\mathrm{H}$, Eklund $\mathrm{C}$, Aaltonen LA, Blomqvist C, Aittomaki K, Nevanlinna H: p53, CHK2, and CHK1 genes in Finnish families with Li-Fraumeni Syndrome: further evidence of CHK2 in inherited cancer predisposition. Cancer Res 2001, 61:5718-5722.

10. Falck J, Mailand N, Syljuasen RG, Bartek J, Lukas J: The ATM-Chk2-Cdc25A checkpoint pathway guards against radioresistant DNA synthesis. Nature 2001, 410:842-847.

11. Meijers-Heijboer $H$, van den Ouweland A, Klijn J, Wasielewski M, de Snoo A, Oldenburg R, Hollestelle A, Houben M, Crepin E, van Veghel-Plandsoen M, Elstrodt F, van Duijn C, Bartels C, Meijers C, Schutte M, McGuffog L, Thompson D, Easton D, Sodha N, Seal S, Barfoot R, Mangion J, Chang-Claude J, Eccles D, Eeles R, Evans DG, Houlston R, Murday V, Narod S, Peretz T, Peto J, Phelan C, Zhang HX, Szabo C, Devilee P, Goldgar D, Futreal PA, Nathanson KL, Weber B, Rahman N, Stratton MR: Low-penetrance susceptibility to breast cancer due to CHEK2*1100delC in noncarriers of BRCA1 or BRCA2 mutations. Nat Genet 2002, 31:3-4.

12. Vahteristo $P$, Bartkova J, Eerola $H$, Syrjakoski $K$, Ojala S, Kilpivaara O, Tamminen A, Kononen J, Aittomaki K, Heikkila P, Holli K, Blomqvist C, Bartek J, Kallioniemi O-P, Nevanlinna H: A CHEK2 genetic variant contributing to a substantial fraction of familial breast cancer. Am J Hum Genet 2002, 71:432-438.

\section{Correspondence}

Jenny Varley, CR-UK Department of Cancer Genetics, Paterson Institute for Cancer Research, Wilmslow Road, Manchester M20 4BX, UK Tel: +44 (0)161 446 3062; fax: +44 (0)161 446 3109; e-mail: jvarley@picr.man.ac.uk 